\title{
Effect of 2-methoxyestradiol on SK-LMS-1 uterine leiomyosarcoma cells
}

\author{
JI-SUN LEE, CHANGHWAN AHN, HEE YOUNG KANG and EUI-BAE JEUNG \\ Laboratory of Veterinary Biochemistry and Molecular Biology, Veterinary Medical Center and College of \\ Veterinary Medicine, Chungbuk National University, Cheongju, Chungbuk 28644, Republic of Korea
}

Received May 12, 2016; Accepted March 7, 2017

DOI: $10.3892 / \mathrm{ol} .2017 .6165$

\begin{abstract}
An endogenous metabolite of $17 \beta$-estradiol, 2-methoxyestradiol (2-ME), has affinity for estrogen receptors. This compound was reported to be a promising antitumor drug due to its anti-proliferative effects on a wide range of tumor cell types. Numerous previous studies have been performed to evaluate the cytotoxic effects of 2-ME on tumor cell lines in following the induction of $\mathrm{G}_{2} / \mathrm{M}$ cell cycle arrest and subsequent apoptosis. Uterine leiomyosarcoma (ULMS) is a relatively rare malignant smooth muscle cell tumor that develops in the uterus muscle layer. The aim of the present study was to examine the in vitro anti-proliferative effects of 2-ME on SK-LMS-1 human leiomyosarcoma cells. An MTT assay, terminal deoxynucleotidyltransferase-mediated dUTP nick-end labeling assay, immunocy tochemistry and western blotting were performed. A high concentration $\left(10^{-5} \mathrm{M}\right)$ of 2-ME was identified to have an anti-proliferative effect on SK-LMS-1 cells. Additionally, expression of the apoptosis markers was upregulated in the presence of $10^{-5} \mathrm{M} 2-\mathrm{ME}$, according to western blot analysis. Furthermore, the expression level of an autophagic marker, light chain 3, was increased by $2-\mathrm{ME}$ treatment in a dose-dependent manner. This was associated with cell death induced by the upregulation of phosphorylated extracellular-signal-regulated kinase 1/2 signaling pathway. The results of the present study demonstrated that 2-ME, which is used as a therapeutic agent for treating solid tumors, exhibits apoptotic and anti-proliferative effects depending on the dose. Therefore, 2-ME may be a potential therapeutic reagent for human ULMS, but the appropriate dose of this compound should be carefully selected.
\end{abstract}

Correspondence to: Professor Eui-Bae Jeung, Laboratory of Veterinary Biochemistry and Molecular Biology, Veterinary Medical Center and College of Veterinary Medicine, Chungbuk National University, 52 Naesudong-ro, Cheongju, Chungbuk 28644, Republic of Korea

E-mail: ebjeung@chungbuk.ac.kr

Key words: uterine leiomyosarcoma, 2-methoxyestrodiol, estrogen metabolite, apoptosis, autophage

\section{Introduction}

Estrogens act as important regulators of cell proliferation, cell survival and differentiation in a variety of organs and tissues, and have been implicated in the etiology of various types of malignant and benign tumors (1). These compounds may induce de novo breast cancer development by receptor-dependent or -independent mechanisms, or actions mediated by the estrogen receptor (ER) (2). A number of estrogen metabolites have also been revealed to be more potent estrogenic compounds compared with their precursor $(3,4)$.

An endogenous estrogen of $17 \beta$-estradiol (E2), 2-methoxyestradiol (2-ME), is produced by sequential hydroxylation of parental compounds followed by methylation by catechol-o-methyltransferase, an enzyme present in numerous tissues including the liver, kidney, brain, placenta, uterus and mammary gland (5). Unlike the growth effects of other estrogen metabolites, including 4-hydroxyestradiol and $16 \alpha$-hydroxyestrone, $2-\mathrm{ME}$ has been reported to elicit antitumor effects on various types of cancer in vitro and in vivo (6-10). A number of mechanisms underlying 2-ME activity have been proposed, including effects on $\mathrm{G}_{2} / \mathrm{M}$ cell-cycle arrest (11). Additionally, this compound is able to induce mitochondrial apoptotic signaling $(8,12)$. In ER-positive MCF7 breast cancer cells, 2-ME was demonstrated to increase p53 expression levels and inhibit proliferation. These results have implications in understanding the role of estrogen metabolite(s) in the regulation of tumor progression (13). In a previous study, apoptosis has received attention, as this process is the primary mechanism underlying the anticancer drug-mediated induction of tumor cell death (14). However, autophagy has recently emerged as a key regulator of cell death pathways, and may be involved in promoting cell death via caspase-dependent and -independent mechanisms $(15,16)$. Furthermore, previous studies have revealed that apoptosis and autophagy share certain common signaling pathways $(16,17)$.

Among the ER-positive tumors, uterine leiomyosarcoma (ULMS) is a relatively rare malignant smooth muscle cell tumor in the uterus muscle layer and is divided into subtypes (18). ULMS accounts for $1 \%$ of all uterine malignancies and $\sim 30 \%$ of all uterine sarcomas including carcinosarcomas, leiomyosarcomas and endometrial stromal sarcomas (19). Although the pathogenesis and molecular events that result in the development of leiomyosarcomas remain largely unknown, 
this malignancy shares similar morphological characteristics with leiomyoma that are considered to promote transformation into ULMS and develop during reproductive years with growth dependent on ovarian steroids $(18,20)$. Local therapy consisting of total hysterectomy and bilateral salpingo-oophorectomy are generally recommended; however, these surgical management strategies may not be appropriate for young patients who desire to preserve their fertility potential (21). Therefore, there is a requirement to develop effective therapeutics that are able to reverse ULMS growth.

To the best of our knowledge, no previous studies have evaluated the growth inhibitory effect of 2-ME on human ULMS. In human clinical trials, 2-ME is well tolerated and was revealed to exhibit low systematic toxicity (6). Therefore, the effects of 2-ME on proliferation and programmed cell death in human ULMS cases were determined in vitro using SK-LMS-1 cells. The present study investigated whether 2-ME may be useful for treating human ULMS.

\section{Materials and methods}

Chemicals. E2 was obtained from Sigma-Aldrich; Merck KGaA (Darmstadt, Germany), Flavopiridol was supplied by Cayman Chemical Company (Ann Arbor, MI, USA) and 2-ME was purchased from Selleck Chemicals (Houston, TX, USA).

Cell culture. SK-LMS-1 cells were obtained from American Type Culture Collection (Manassas, VA, USA). Cells were grown as monolayer cultures in Dulbecco's modified Eagle's medium (Gibco; Thermo Fisher Scientific, Inc., Waltham, MA, USA), supplemented with $10 \%$ fetal bovine serum (FBS; Gibco; Thermo Fisher Scientific, Inc.), $100 \mathrm{U} / \mathrm{ml}$ penicillin and $100 \mu \mathrm{g} / \mathrm{ml}$ streptomycin (Gibco; Thermo Fisher Scientific, Inc.) at $37^{\circ} \mathrm{C}$ in a humidified atmosphere containing $95 \% \mathrm{O}_{2}$ and $5 \% \mathrm{CO}_{2}$. SK-LMS-1 cells were plated on 6-well plastic tissue culture dishes (Nalge Nunc International; Thermo Fisher Scientific, Inc.) at a density of $3 \times 10^{4}$ cells/well and grown for $24 \mathrm{~h}$ at $37^{\circ} \mathrm{C}$. The medium was replaced with phenol red-free Opti-MEM (Gibco; Thermo Fisher Scientific, Inc.) supplemented with 5\% charcoal dextran-stripped FBS and $100 \mathrm{U} / \mathrm{ml}$ penicillin-streptomycin for $48 \mathrm{~h}$ to ensure the depletion of steroid hormones in the cells at $37^{\circ} \mathrm{C}$. Following $48 \mathrm{~h}$, the cells were exposed to various doses of 2-ME $\left(10^{-7}\right.$, $10^{-6}$ and $\left.10^{-5} \mathrm{M}\right)$ and Flavopiridol $\left(2 \times 10^{-6}\right.$ and $\left.4 \times 10^{-6} \mathrm{M}\right)$. Each chemical was dissolved in $100 \%$ dimethyl sulfoxide (DMSO) (Santa Cruz Biotechnology, Inc., Dallas, TX, USA) and added to phenol red-free Opti-MEM containing 5\% FBS and charcoal-dextran (starvation medium) with a final DMSO concentration of $0.1 \%$. Starvation medium containing $2 \times 10^{-6}$ or $4 \times 10^{-6} \mathrm{M}$ Flavopiridol were used as positive controls (22) and starvation medium containing 0.1\% DMSO was used as a negative control (vehicle). SK-LMS-1 cells were harvested $24 \mathrm{~h}$ after treatment for evaluation of protein levels. All experiments were performed in triplicate.

Cell viability assay. An MTT assay was performed to confirm the viability of the endometrial cancer cells. SK-LMS-1 cells $\left(1.0 \times 10^{3}\right.$ cells/well) were seeded in 96-well plates for $24 \mathrm{~h}$ in an incubator at $37^{\circ} \mathrm{C}$. The following day, the medium was replaced with phenol red-free Opti-MEM supplemented with 5\% charcoal dextran-stripped FBS and $100 \mathrm{U} / \mathrm{ml}$ penicillin-streptomycin in SK-LMS-1 cells for $48 \mathrm{~h}$. After $48 \mathrm{~h}$, the cells were exposed to E2 $\left(10^{-9} \mathrm{M}\right), 2-\mathrm{ME}\left(10^{-7}, 10^{-6}\right.$ and $\left.10^{-5} \mathrm{M}\right)$ and Flavopiridol $\left(2 \times 10^{-6}\right.$ and $\left.4 \times 10^{-6} \mathrm{M}\right)$ for $24 \mathrm{~h}$. Subsequently, an MTT assay was performed to determine cell viability. A total of $5 \mathrm{mg} / \mathrm{ml}$ MTT stock solution (Sigma-Aldrich; Merck KGaA) was diluted in PBS, then $20 \mu$ l MTT stock solution was added to each well and the plates were incubated at $37^{\circ} \mathrm{C}$ for $4 \mathrm{~h}$. The yellow formazan crystals that formed were dissolved in $80 \mu \mathrm{l}$ DMSO. Following agitation, the absorbance was evaluated at $560 \mathrm{~nm}$ using an ELISA plate reader. Each experiment was performed in triplicate $(n=6)$.

Terminal deoxynucleotidyltransferase-mediated dUTP nick-end labeling (TUNEL) assay. The TUNEL assay was performed on chamber slides (Thermo Fisher Scientific, Inc.) using the In Situ Cell Death Detection kit, Fluorescein (Roche Diagnostics GmbH, Mannheim, Germany). SK-LMS-1 cells were fixed in $4 \%$ paraformaldehyde. The cells were then rinsed with PBS and incubated in blocking solution $\left(3 \% \mathrm{H}_{2} \mathrm{O}_{2}\right.$ in methanol) for $10 \mathrm{~min}$ at room temperature and subsequently washed with PBS. Subsequently, cells were permeabilized with $0.1 \%$ Triton X-100 (Amresco, LLC, Solon, OH, USA) in $0.1 \%$ sodium citrate for $2 \mathrm{~min}$ on ice and then cells were washed with PBS and the area around the sample was dried. The cells were incubated with $50 \mu 1$ TUNEL reaction mixture at $37^{\circ} \mathrm{C}$ for $60 \mathrm{~min}$ in a dark humidified atmosphere. Using a BX51 fluorescence microscope (Olympus Corporation, Tokyo Japan) the numbers of TUNEL-positive cells were counted using fluorescence microscopy. Positive control sections were treated with the same reagents and pre-treated with $1,000 \mathrm{U} / \mathrm{ml}$ DNase I (Takara Bio Inc., Otsu, Japan) for $10 \mathrm{~min}$ at room temperature prior to the TUNEL assay (data not shown). The nuclei were stained with DAPI at $2 \mu \mathrm{g} / \mathrm{ml}$ (Sigma-Aldrich; Merck KGaA).

Immunocytochemistry. The SK-LMS- 1 cells $\left(1.0 \times 10^{3}\right.$ cells/well) were cultured on 4-well plates (Nalge Nunc International; Thermo Fisher Scientific, Inc.) for $24 \mathrm{~h}$ in an incubator at $37^{\circ}$. The following day, the medium was replaced with phenol red-free Opti-MEM supplemented with 5\% charcoal dextran-stripped FBS and $100 \mathrm{U} / \mathrm{ml}$ penicillin-streptomycin in SK-LMS-1 cells for $48 \mathrm{~h}$ at $37^{\circ} \mathrm{C}$. Following $48 \mathrm{~h}$, the cells were exposed to $2-\mathrm{ME}\left(10^{-7}, 10^{-6}\right.$ and $\left.10^{-5} \mathrm{M}\right)$ and Flavopiridol $\left(2 \times 10^{-6}\right.$ and $\left.4 \times 10^{-6} \mathrm{M}\right)$ for $24 \mathrm{~h}$ at $37^{\circ} \mathrm{C}$. For the staining procedure, the SK-LMS-1 cells were fixed in $4 \%$ paraformaldehyde/PBS for $15 \mathrm{~min}$ at room temperature and in $100 \%$ methanol (chilled at $-20^{\circ} \mathrm{C}$ ) at room temperature for $10 \mathrm{~min}$ and then cells were immediately washed three times with PBS. The cells were permeabilized with $0.2 \%$ Triton X-100 in PBS for $10 \mathrm{~min}$ at room temperature and washed twice for $5 \mathrm{~min}$ with PBS. Subsequently, the cells were incubated for $60 \mathrm{~min}$ in a blocking solution [PBS/5\% bovine serum albumin (BSA)] at room temperature. The primary antibody against light chain 3 (LC3; \#4108; Cell Signaling Technology Inc., Danvers, MA, USA) was diluted 1:200 in PBS, 5\% BSA and 0.3\% Triton $\mathrm{X}-100$. Following incubation with the primary antibodies overnight at $4^{\circ} \mathrm{C}$, the cells were washed three times for $5 \mathrm{~min}$ with PBS and then incubated with DyLight 550 conjugated goat anti-rabbit IgG (heavy and light chains; dilution, 1:250 in 


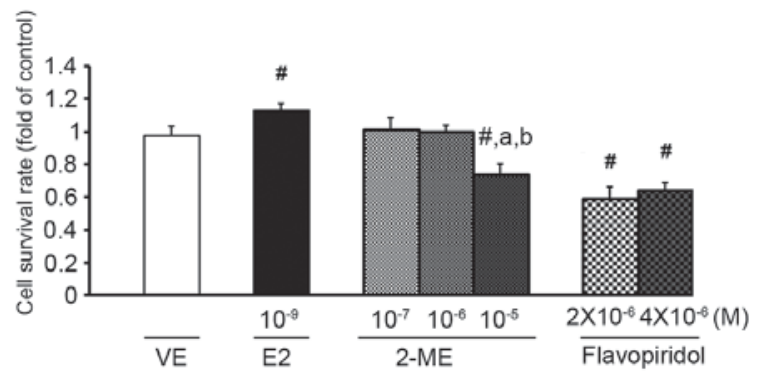

Figure 1. Viability of SK-LMS-1 cells is 2-ME concentration-dependent. Cells were treated with VE ( $0.1 \%$ dimethyl sulfoxide), various concentrations of 2-ME $\left(10^{-7}, 10^{-6}\right.$ and $\left.10^{-5} \mathrm{M}\right)$ and Flavopiridol $\left(2 \times 10^{-6}\right.$ and $\left.4 \times 10^{-6} \mathrm{M}\right)$ for $24 \mathrm{~h}$. Results are presented as the mean \pm standard error of the mean of quadruplicates for three separate experiments. ${ }^{\prime \prime} \mathrm{P}<0.05$ vs. VE; ${ }^{a} \mathrm{P}<0.05$ vs 2 -ME $\left(10^{-7} \mathrm{M}\right) ;{ }^{\text {b }} \mathrm{P}<0.05$ vs. 2 -ME $\left(10^{-6} \mathrm{M}\right)$. VE, vehicle; E2, $17 \beta$-estradiol; 2-ME, 2-methoxyestradiol.

PBS, \#84541; Thermo Fisher Scientific, Inc.) for $1 \mathrm{~h}$ at room temperature. Cells were then washed three times for $5 \mathrm{~min}$ with PBS and incubated with $2 \mu \mathrm{g} / \mathrm{ml}$ DAPI to stain the nuclei for $5 \mathrm{~min}$ at room temperature in the dark. Images of the cells were captured using a BX51 fluorescence microscope.

Western blot analysis. Cellular protein was extracted using radioimmunoprecipitation assay buffer $(50 \mathrm{mM}$ Tris- $\mathrm{HCl}$, $\mathrm{pH}$ 7.4, $150 \mathrm{mM} \mathrm{NaCl}, 1 \% \mathrm{NP}-40,0.25 \%$ sodium deoxycholate, $1 \mathrm{mM}$ PMSF, $1 \mathrm{mM}$ EDTA and proteinase inhibitor cocktail (no. S8830; Sigma-Aldrich; Merck KGaA) and was rapidly excised and washed in ice-cold sterile $0.9 \% \mathrm{NaCl}$. Soluble proteins were extracted using Proprep (Intron Biotechnology, Inc., Seongnam, Korea). Protein concentration was determined using the bicinchoninic acid assay (Sigma-Aldrich; Merck $\mathrm{KGaA}$ ). A total of $40 \mu \mathrm{g}$ protein per lane was separated using SDS-PAGE (10-15\% gel) and then transferred onto polyvinylidene fluoride transfer membranes (Merck KGaA). The membranes were blocked in Tris-buffered saline with 5\% Tween-20 (TBS-T) supplemented with 5\% skimmed milk for $60 \mathrm{~min}$ at room temperature and then incubated with primary antibodies against B-cell lymphoma 2-associated X protein (Bax; 1:1,000; no. sc-493; Santa Cruz Biotechnology, Inc.), B-cell lymphoma-2 (Bcl-2; 1:1,000; no. sc-509; Santa Cruz Biotechnology, Inc.), p53 (1:1,000; no. sc-377567; Santa Cruz Biotechnology, Inc.), caspase-3 (1:1,000; no. 9662; Cell Signaling Technology Inc.), LC3 (1:1,000; no. 4108; Cell Signaling Technology Inc.), protein kinase B (Akt; 1:1,000; no. sc-11520 Santa Cruz Biotechnology, Inc.), phosphorylated (p)-Akt (1:1,000; no. sc-33437; Santa Cruz Biotechnology, Inc.), extracellular-signal-related kinase (ERK) 1/2 (1:1,000; no. 9102; Cell Signaling Technology Inc.), p-ERK1/2 (1:1,000; no. 4370; Cell Signaling Technology Inc.) and $\alpha$-tubulin $(1: 1,000)$ at $4^{\circ} \mathrm{C}$ overnight. Following washing in TBS-T, the membranes were incubated with the appropriate horseradish peroxidase-conjugated secondary antibodies (anti-rabbit; 1:3,000; no. sc-2004; Santa Cruz Biotechnology, Inc.; or anti-mouse; 1:3,000; no. bs-0296G; BIOSS, Beijing, China) for $2 \mathrm{~h}$ at room temperature. Following washing of the membranes with TBS-T, antibody binding was detected using an enhanced chemiluminescence reagent (Santa Cruz Biotechnology, Inc.) and detected using ChemiDoc equipment GeneGnome 5
(Syngene, Frederick, MD, USA). Optical density of the target band was analyzed using ImageJ software (Version 1.50e; National Institutes of Health, Bethesda, MD, USA).

Statistical analysis. The experiments were performed in triplicate. Results are presented as the mean \pm standard error of the mean. P-values were determined using one-way analysis of variance, followed by Tukey's test for multiple comparisons of columns. $\mathrm{P}<0.05$ was considered to indicate a statistically significant difference.

\section{Results}

2-ME exerts an anti-proliferative effect on ULMS cells. To determine whether 2-ME influenced the viability of ULMS cells, SK-LMS-1 cells were incubated for $24 \mathrm{~h}$ with $2-\mathrm{ME}\left(10^{-7}\right.$, $10^{-6}$ and $\left.10^{-5} \mathrm{M}\right)$. Flavopiridol and E2 were used as the controls. Flavopiridol, a synthetic derivative isolated initially from the stem bark of Dysoxylum binectariferum, is a pan inhibitor of cyclin-dependent kinases and is capable of inducing either cell cycle arrest or apoptosis (22). Concentrations of the chemicals were based on results from previous studies $(9,22)$. As presented in Fig. 1, analysis of cell cytotoxicity was determined using an MTT assay and indicated that $10^{-9} \mathrm{M}$ E2 significantly increased cell proliferation. In contrast, treatment with $10^{-5} \mathrm{M}$ 2-ME or flavopiridol resulted in cell cytotoxicity (Fig. 1).

2-ME exerts a cytotoxic effect on ULMS cells via apoptosis. To examine apoptosis induced by 2 -ME $\left(10^{-5} \mathrm{M}\right)$, DNA fragmentation was visualized using a TUNEL assay. As presented in Fig. 2, SK-LMS-1 cells treated with $10^{-5} \mathrm{M}$ 2-ME and $4 \times 10^{-6} \mathrm{M}$ flavopiridol exhibited increased levels of green fluorescent signals compared with those treated with the vehicle. TUNEL-positive cells were counted and compared with the number of nuclei (blue signals) as morphological differences were observed between cells treated with 2-ME or flavopiridol. The results revealed that $88.5 \%$ of SK-LMS-1 cells incubated with 2-ME $\left(10^{-5} \mathrm{M}\right)$ were TUNEL-positive and $96.9 \%$ of the flavopiridol-treated cells were TUNEL-positive. Treatment with $10^{-5} \mathrm{M} 2-\mathrm{ME}$ was therefore revealed to increase the number of apoptotic cells based on DNA fragmentation compared with the untreated group (Fig. 2). To confirm that cell death induced by 2 -ME was due to apoptosis, cell lysates were analyzed for the expression of apoptosis markers Bax, Bcl-2, caspase-3 and p53 by western blotting. Bax is a member of the Bcl-2 family that promotes apoptosis and the ratio of $\mathrm{Bax} / \mathrm{Bcl}-2$ determines the sensitivity of a cell to apoptosis (23). Caspases, particularly caspase-3, are known to act downstream of Bax/Bcl-2 and serve a key role in apoptosis (24). p53 has the ability to activate transcription of various pro-apoptotic genes, including those encoding members of the Bcl-2 family, and may also trigger apoptosis (25). As presented in Fig. 3, caspase-3 protein expression level was significantly increased following treatment with $2-\mathrm{ME}\left(10^{-5} \mathrm{M}\right)$ or flavopiridol

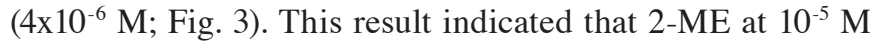
exerted an anti-proliferative effect on ULMS cells via the induction of apoptosis.

2-ME upregulates $p$-ERK1/2 signaling in ULMS cells. It has been reported that ERK/mitogen-activated protein kinase 

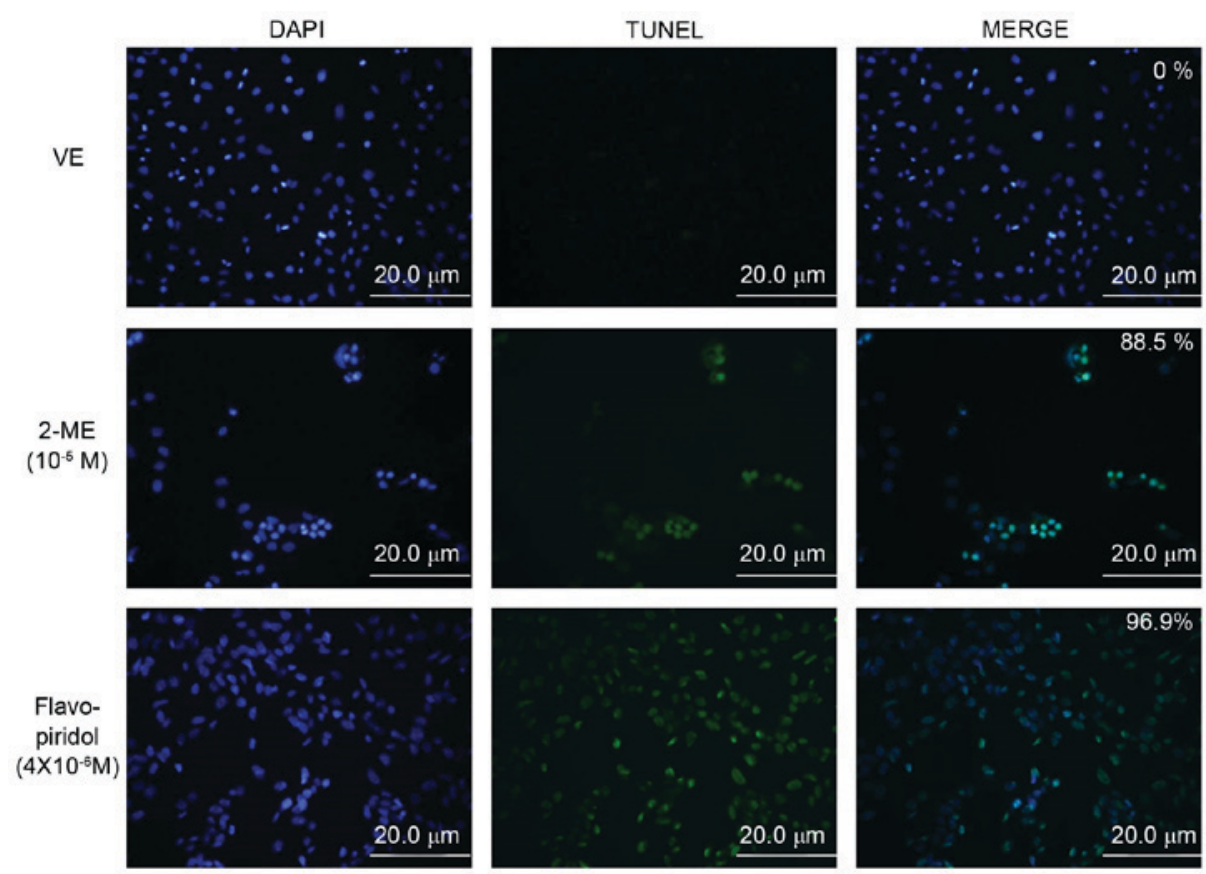

Figure 2. DNA fragmentation is increased in SK-LMS-1 cells at the highest concentration of 2-ME. Cells were treated with VE ( $0.1 \%$ dimethyl sulfoxide), 2-ME $\left(10^{-5} \mathrm{M}\right)$ and Flavopiridol $\left(4 \times 10^{-6} \mathrm{M}\right)$ for $24 \mathrm{~h}$. SK-LMS-1 cell death and DNA fragmentation were evaluated using a TUNEL assay. Immunofluorescence detection identified DNA stand breaks (green) and nuclei stained with DAPI (blue). Scale bar, $20 \mu \mathrm{m}$. VE, vehicle; 2-ME, 2-methoxyestradiol. TUNEL, terminal deoxynucleotidyltransferase-mediated dUTP nick-end labeling.

positively regulated the phosphorylation of Bcl-2 at $\mathrm{Ser}^{70}$, inducing suppressed Bcl-2 expression (26). In order to determine whether 2-ME influenced intrinsic apoptotic signaling via the ERK1/2 signaling pathways, western blotting was performed, as presented in Fig. 4A. The expression levels of p-ERK1/2 and ERK1/2 were significantly upregulated in ULMS cells following treatment with $10^{-5} \mathrm{M} 2$-ME and flavopiridol $\left(2 \times 10^{-6}\right.$ and $\left.4 \times 10^{-6} \mathrm{M}\right)$ for $24 \mathrm{~h}$ (Fig. 4A). However, the $\mathrm{p}$-Akt/Akt expression level was decreased in the presence of 2-ME $\left(10^{-5} \mathrm{M}\right.$; Fig. 4B). The downregulation/inactivation of Akt has been reported to serve a key role in mediating the cytotoxic effects of 2-ME in human leukemia cells (27). However, the results of the present study demonstrated that the p-Akt/Akt expression level in ULMS cells was not significantly affected by $2-\mathrm{ME}$ at any of the doses investigated $\left(10^{-7}\right.$, $10^{-6}$ or $10^{-5} \mathrm{M}$ ) compared with the vehicle (Fig. 4B). Therefore, the results indicated that 2-ME-induced apoptosis is mediated by the activation of the (p)-ERK1/2 signaling pathway in ULMS cells.

2-ME enhances autophagy in ULMS cells. Evaluation of apoptosis in tumor cells has been identified to be an important factor for detecting the ability of therapeutic drugs to prevent tumor growth. However, numerous previous studies have demonstrated that autophagy is also a cell death mechanism that may occur in the absence of detectable signs of apoptosis or concomitantly with apoptosis (14). To determine whether 2-ME induces autophagy, the LC3 expression level was evaluated using immunocytochemistry (Fig. 5A). In cells treated with $10^{-5} \mathrm{M} 2-\mathrm{ME}$, a marked LC3 expression level was detected, indicating that 2-ME induced the formation of autophagosomes in ULMS cells. To further confirm that 2-ME induced autophagy, western blotting was also performed. As presented in Fig. 5B, LC3 expression level increased in the presence of 2-ME $\left(10^{-7}, 10^{-6}\right.$ and $\left.10^{-5} \mathrm{M}\right)$. Flavopiridol also elevated LC 3 expression levels at a concentration of $4 \times 10^{-6}$ M. Additionally, the LC3-II expression level was significantly increased with $10^{-5} \mathrm{M} 2-\mathrm{ME}$ and $2 \times 10^{-6} \mathrm{M}$ flavopiridol compared with the vehicle (Fig. 5B). During the autophagy cascade, LC3-I is converted into LC-II via lipidation by an ubiquitin-like system. LC3-II then remains with autophagosomes until fusion with lysosomes is completed and it may therefore be used as a marker of autophagy (28). Consequently, results from the present study indicated that $2-\mathrm{ME}$ induced autophagy in SK-LMS-1 cells.

\section{Discussion}

The estrogen metabolite 2-ME has been reported to inhibit cell proliferation by apoptosis in a wide range of tumor cells (7-9). In cases of uterine leiomyoma, 2-ME was identified to exert an anti-proliferative effect by arrest in the $\mathrm{G}_{2} / \mathrm{M}$ phase and inhibited collagen synthesis (29). Uterine leiomyomas, or fibroids, are benign smooth muscle cell tumors and are the most common type of pelvic tumors in females (30). These lesions are estrogen/progesterone-dependent and occur primarily during the reproductive years (29).

Ovarian steroid hormones, particularly estrogen, mediate uterine leiomyoma development. Leiomyoma has been reported to progress with estrogen stimulation (31). ULMS, a rare type of uterine tumor, accounts for between 1 and $2 \%$ of uterine malignancies, and has symptoms similar to those of common leiomyoma along with preoperative distinction (19). It was also reported that ULMS tissue expressed ERs and progesterone receptors (32). ULMS poses a threat to females of reproductive age, particularly since there are no effective 


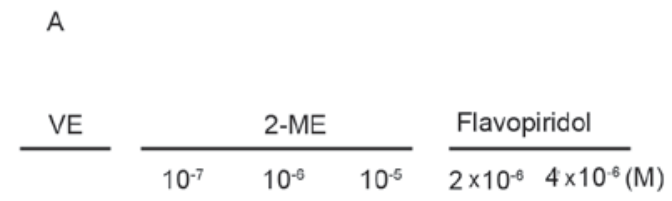

B
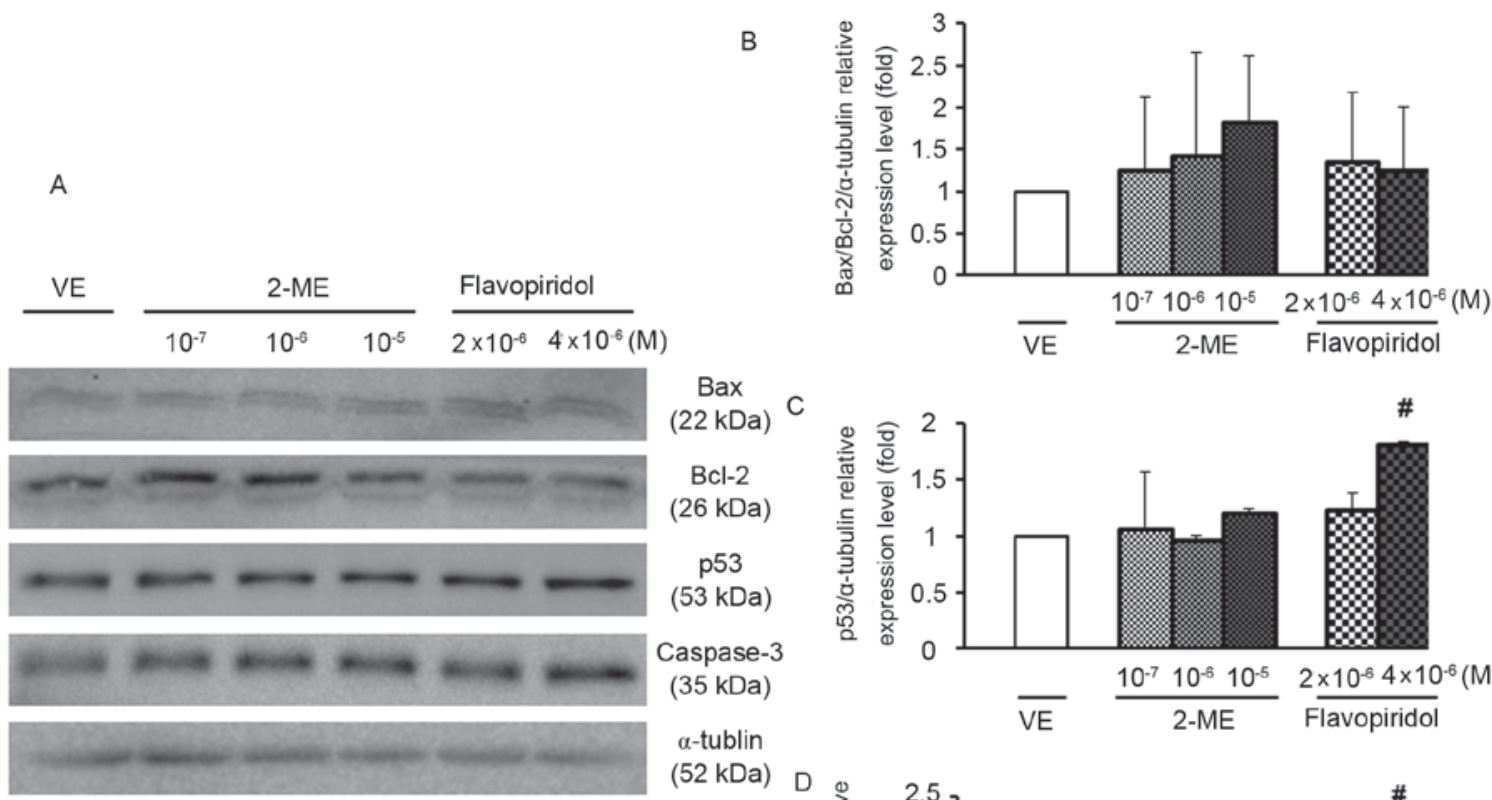

$\mathrm{Bax}$
$22 \mathrm{kDa})$

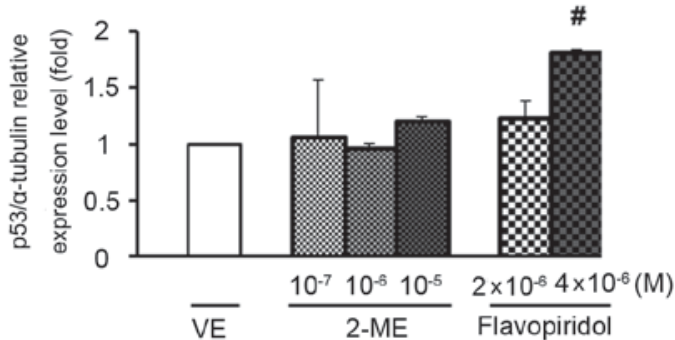

$(52 \mathrm{kDa})$

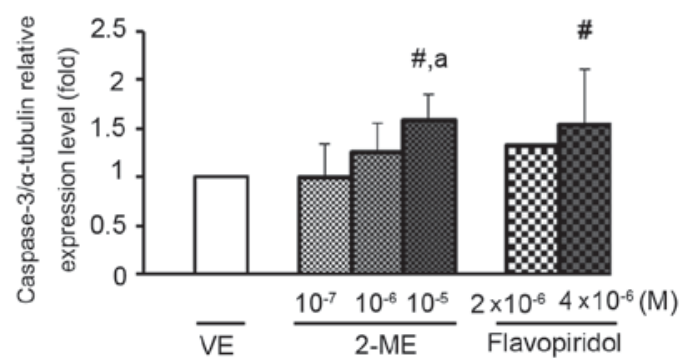

Figure 3. Protein expression levels of apoptosis markers in SK-LMS-1 cells are 2-ME concentration-dependent. Cells were treated with VE (0.1\% dimethyl sulfoxide), various concentrations of 2-ME $\left(10^{-7}, 10^{-6}\right.$ and $\left.10^{-5} \mathrm{M}\right)$ and Flavopiridol $\left(2 \times 10^{-6}\right.$ and $\left.4 \times 10^{-6} \mathrm{M}\right)$ for $24 \mathrm{~h}$. (A) Protein expression levels of Bax/Bcl-2, p53 and caspase-3 were determined by western blotting. Each protein was normalized relative to $\alpha$-tubulin and quantifications of (B) Bax/Bcl-2, (C) p53 and (D) caspase-3 expression levels in SK-LMS-1 cells were analyzed using ImageJ. ${ }^{*} \mathrm{P}<0.05$ vs. VE; ${ }^{a} \mathrm{P}<0.05$ vs. 2-ME (10-7 M). VE, vehicle; 2 -ME, 2-methoxyestradiol; Bax, Bcl-2-associated X protein; Bcl-2, B-cell lymphoma-2.

A
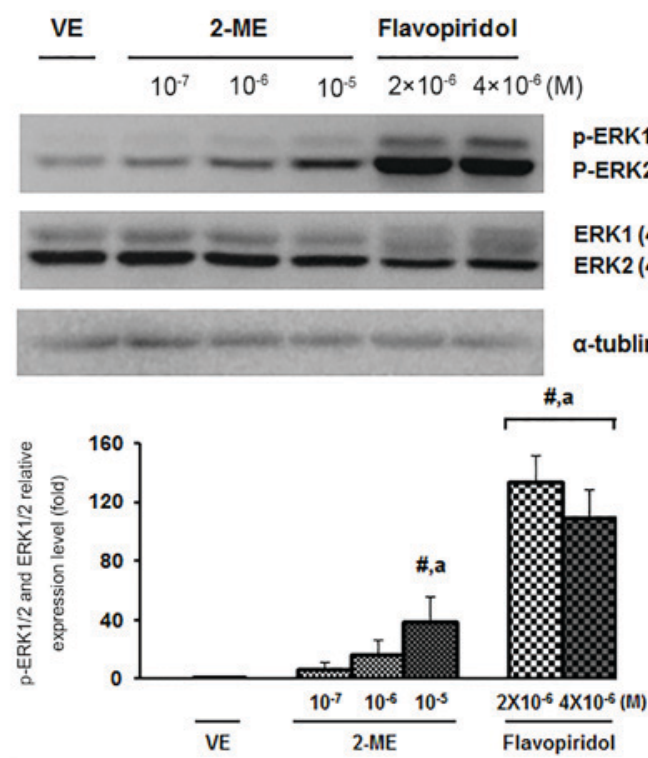

B
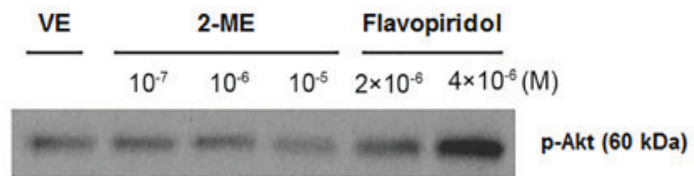

P-ERK2 (42 kDa)

ERK1 (44 kDa)

ERK2 (42 kDa)

a-tublin (52 kDa)
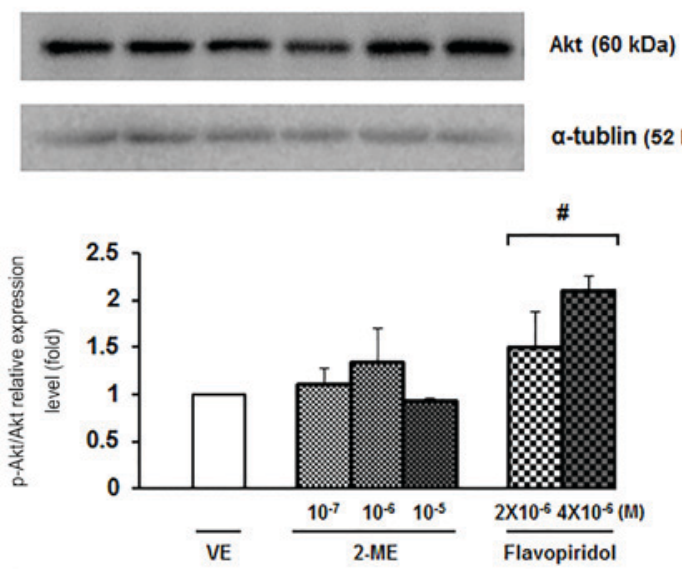

Figure 4. Protein expression levels of ERK1/2 and Akt in SK-LMS-1 cells are 2-ME concentration-dependent. Cells were treated with VE (0.1\% dimethyl sulfoxide), various concentrations of 2-ME $\left(10^{-7}, 10^{-6}\right.$ and $\left.10^{-5} \mathrm{M}\right)$ and Flavopiridol $\left(2 \times 10^{-6}\right.$ and $\left.4 \times 10^{-6} \mathrm{M}\right)$ for 24 h. (A) Protein expression levels of p-ERK1/2 and ERK1/2 were determined by western blotting. (B) Protein expression levels of p-Akt and Akt were determined by western blotting. Each protein was normalized relative to $\alpha$-tubulin and quantifications of (A) p-ERK1/2 and ERK1/2 and (B) p-Akt and Akt in SK-LMS-1 cells were analyzed using ImageJ. ${ }^{\#} \mathrm{P}<0.05$ vs. VE; ${ }^{a} \mathrm{P}<0.05$ vs. 2-ME $\left(10^{-7} \mathrm{M}\right)$. VE, vehicle; 2-ME, 2-methoxyestradiol; ERK, extracellular-signal-related kinase; p, phosphorylated; Akt, protein kinase $\mathrm{B}$. 
A

VE
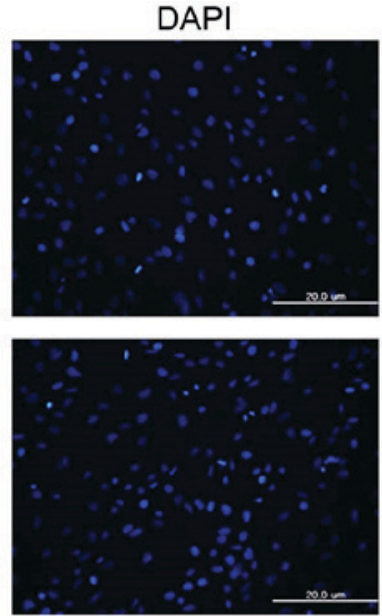

2-ME

$\left(10^{-7} \mathrm{M}\right)$

2-ME

$\left(10^{-6} \mathrm{M}\right)$
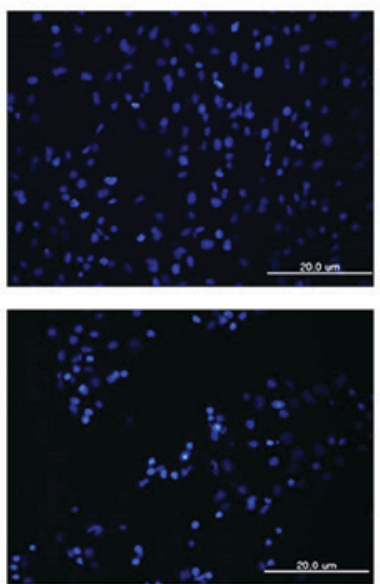

2-ME $\left(10^{-5} \mathrm{M}\right)$
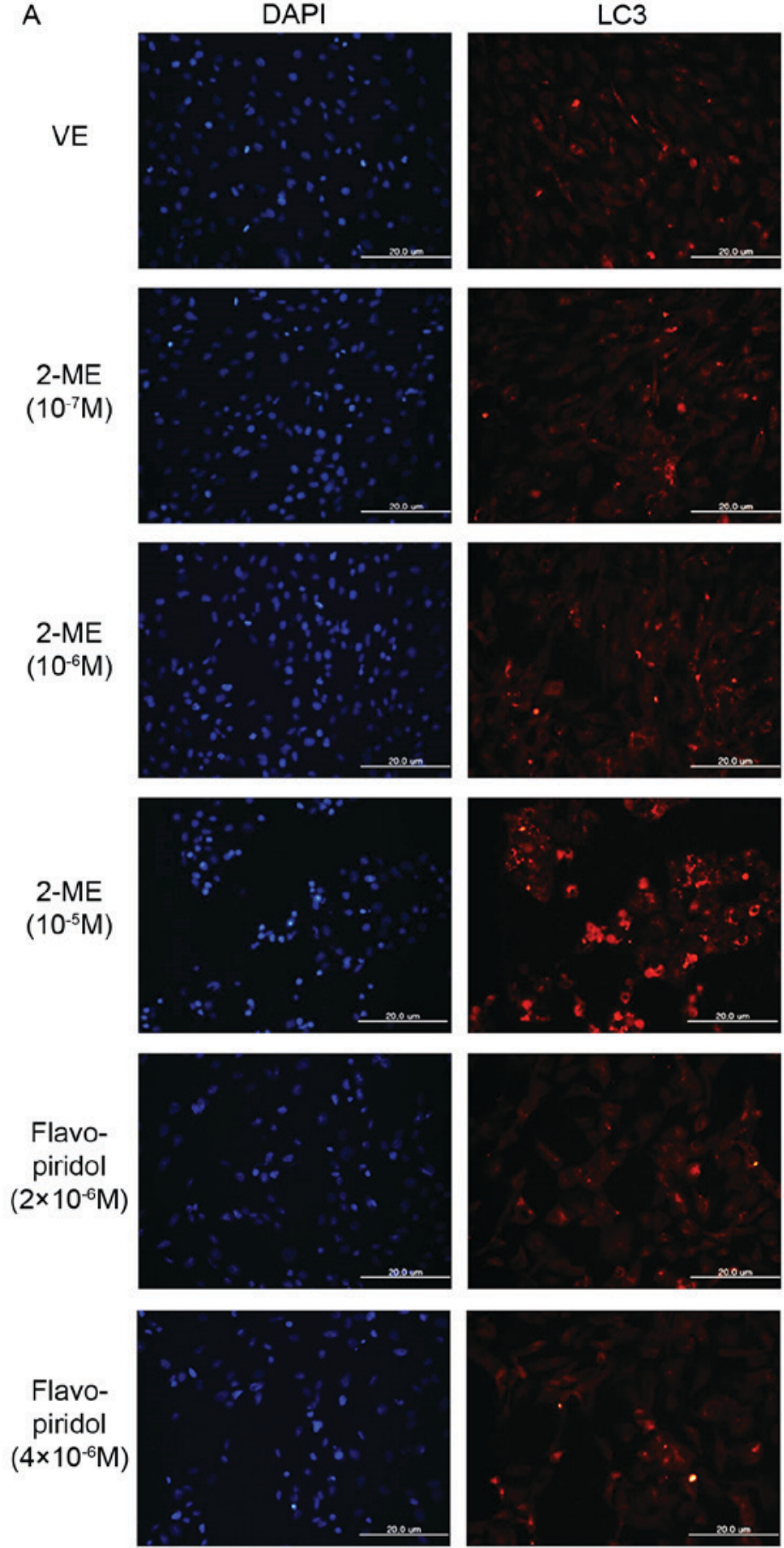

B

$$
\frac{\text { VE }}{} \frac{2-\mathrm{ME}}{10^{7} \quad 10^{6} \quad 10^{5}} \frac{\text { Flavopinidol }}{2 \times 10^{6} \quad 4 \times 10^{-6}(\mathrm{M})}
$$
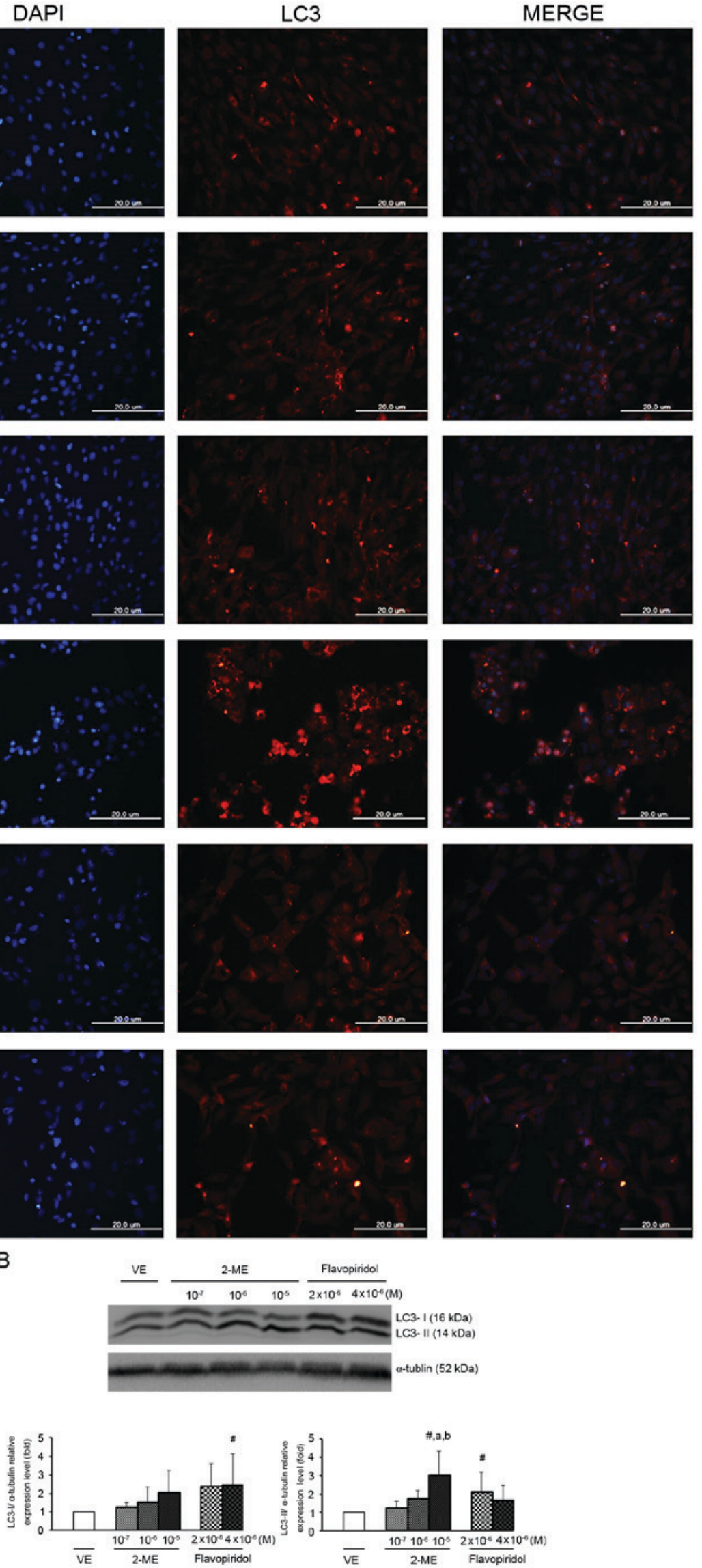

Figure 5. LC3 expression in SK-LMS-1 cells is 2-ME concentration-dependent. Cells were treated with VE (0.1\% dimethyl sulfoxide), various concentrations of 2-ME $\left(10^{-7}, 10^{-6}\right.$ and $\left.10^{-5} \mathrm{M}\right)$ and Flavopiridol $\left(2 \times 10^{-6}\right.$ and $\left.4 \times 10^{-6} \mathrm{M}\right)$ for $24 \mathrm{~h}$. (A) Detection of LC3 by immunofluorescence. Immunofluorescence detection revealed LC3 staining (red) and nuclei stained with DAPI (blue). Scale bar, $20 \mu \mathrm{m}$. (B) Protein expression levels of LC3 were determined by western blotting. LC3-I and LC3-II were normalized relative to $\alpha$-tublin and quantification of LC3-I and LC3-II in SK-LMS-1 cells was analyzed using ImageJ. ${ }^{*} \mathrm{P}<0.05$ vs. VE; ${ }^{\mathrm{a}} \mathrm{P}<0.05$ vs. 2 -ME $\left(10^{-7} \mathrm{M}\right)$; ${ }^{\mathrm{b}} \mathrm{P}<0.05$ vs. 2 -ME $\left(10^{-6} \mathrm{M}\right)$. VE, vehicle; E2, 17ß-estradiol; 2-ME, 2-methoxyestradiol; LC3, light chain 3. 
and safe medications for treating this disease. Surgical procedures including hysterectomy or myomectomy are the primary option for treatment (21). Therefore, there is a requirement for novel drugs or compounds that may be effective therapies for ULMS.

In the present study, 2-ME was demonstrated to exhibit antitumor activity that resulted in autophagic and apoptotic death of ULMS cells. The results revealed that the anti-proliferative effects of 2-ME occur only at a concentration of $10^{-5} \mathrm{M}$ in SK-LMS-1 cells. Consistent with previous studies $(8,9), 10^{-5} \mathrm{M}$ 2-ME induced growth inhibition and apoptosis. Similar to numerous other types of tumor, homeostatic control of the growth of leiomyosarcoma is hypothesized to be the result of the dynamic balance between cell proliferation and cell death (29). In the present study, 2-ME decreased the expression level of the anti-apoptotic protein Bcl-2. This factor promotes cell survival and extends the lifespan of certain cells (33). Additionally, treatment with 2-ME and flavopiridol does not affect the expression level of the pro-apoptotic protein Bax. Therefore, treatment of ULMS cells with 2-ME increased the ratio of $\mathrm{Bax} / \mathrm{Bcl}-2$, which reflected the induction of apoptosis. Similarly, Joubert et al (34) reported that treatment of esophageal carcinoma cells with 2-ME significantly decreased Bcl-2 expression levels without affecting Bax expression level (34). Furthermore, 2-ME was reported to induce apoptosis as a result of c-Jun N-terminal kinase, ERK and p38 kinase activation, in addition to activation of the intrinsic apoptotic pathway via inactivation of $\mathrm{Bcl}-2$ and $\mathrm{Bcl}$-extra large proteins. Upregulation of the extrinsic signaling pathway by increased expression level of death receptor 5 induced activation of caspase- 8 has also been observed $(35,36)$.

Caspases are crucial mediators of programmed cell death, including apoptosis. Among these factors, caspase-3 is a frequently activated death protease that induces DNA fragmentation (37). Results of the present study demonstrated that 2-ME induced the apoptotic death of SK-LMS-1 cells by increasing protein levels of caspase-3 and DNA fragmentation (TUNEL-positive cells).

The tumor suppressor gene p53 is an important regulator of apoptosis. Normally, this factor prevents the replication of damaged DNA by inducing $\mathrm{G}_{1} / \mathrm{S}$ cell cycle arrest or apoptosis . Increased p53 protein expression level induced by 2-ME has also been observed in colorectal cancer cells (7). However, the expression level of p53 was not significantly increased in the present study.

It has been well established that ERK1/2 activation serves a role in proliferative signaling pathways (38); however, this activation was previously reported to aid ERK1/2 phosphorylation involved in apoptotic events (39). Tsai et al (40) demonstrated that upregulation of the ERK signaling pathway was associated with the mitochondria-dependent apoptotic signaling pathway in MDA-MB-468 human breast cancer cells and positively regulated the phosphorylation of $\mathrm{Bcl}-2$ at $\mathrm{Ser}^{70}$, thus inhibiting Bcl-2 expression (40). It has also been revealed that ERK activation cooperatively acts with p53 to promote apoptosis or cell cycle arrest in numerous cell lines (41). In the present study, increasing the phosphorylation of ERK1/2 using $10^{-5} \mathrm{M}$ 2-ME in SK-LMS-1 cells indicated that the intrinsic pathway was upregulated by death signals to mitochondria-dependent associated apoptosis.
The phosphatidylinositol 3-kinase/Akt signal transduction pathway serves an important role in cell survival decisions (42). In human leukemia cells, 2-ME-induced-Akt inactivation demonstrated a critical functional role in mediating 2-ME lethality (27). However, phosphorylation of Akt was not affected in SK-LMS-1 cells by 2-ME at any concentration, which revealed that 2-ME-induced apoptosis occurs via an intrinsic signaling pathway associated with the upregulation of ERK1/2 activity.

The role of the ERK signaling pathway in the induction of cell death should not be restricted to apoptosis (i.e., caspase-dependent cell death). Under certain conditions, autophagy induces cell death associated with ERK activity. ERK-dependent autophagic activity is associated with classical markers of autophagy, including the induction of LC3 activity and conversion of LC3-I into LC3-II $(43,44)$. Similarly, the results of the present study demonstrated that 2-ME activated the ERK signaling pathway, which may mediate autophagic type II programmed cell death by increasing LC3 expression level in SK-LMS-1 cells.

The results of the present study indicated that 2-ME, a well-tolerated natural metabolite of E2, exerted anti-proliferative effects on human ULMS cells at a concentration of $10^{-5} \mathrm{M}$. This compound inhibited cell proliferation by inducing apoptosis and autophagy. However, in a previous study, treatment with 2-ME at concentrations lower than anticancer therapeutic concentrations, revealed an estrogenic effect based on uterine weight gain and increasing expression levels of estrogen biomarkers in in vitro and in vivo models (45). Therefore, it may affect the estrogen and/or progesterone receptor, and retaining 2-ME in the body may be affect endocrine homeostasis and its function. Therefore, careful selection of the optimal dose of 2-ME is required for treating human ULMS.

\section{Acknowledgements}

The present study was supported by the National Research Foundation of Korea grant of the Korean government (MEST; grant no. 2017R1A2B2005031).

\section{References}

1. Spady TJ, McComb RD and Shull JD: Estrogen action in the regulation of cell proliferation, cell survival, and tumorigenesis in the rat anterior pituitary gland. Endocrine 11: 217-233, 1999.

2. Yue W, Yager JD, Wang JP, Jupe ER and Santen RJ: Estrogen receptor-dependent and independent mechanisms of breast cancer carcinogenesis. Steroids 78: 161-170, 2013.

3. Nandi S, Guzman RC and Yang J: Hormones and mammary carcinogenesis in mice, rats, and humans: A unifying hypothesis. Proc Natl Acad Sci USA 92: 3650-3657, 1995.

4. Seegers JC, Aveling ML, Van Aswegen CH, Cross M, Koch F and Joubert WS: The cytotoxic effects of estradiol-17 beta, catecholestradiols and methoxyestradiols on dividing MCF-7 and HeLa cells. J Steroid Biochem 32: 797-809, 1989.

5. Zhu BT and Conney AH: Is 2-methoxyestradiol an endogenous estrogen metabolite that inhibits mammary carcinogenesis? Cancer Res 58: 2269-2277, 1998.

6. LakhaniNJ,SarkarMA,VenitzJandFiggWD:2-Methoxyestradiol, a promising anticancer agent. Pharmacotherapy 23: 165-172, 2003.

7. Carothers AM, Hughes SA, Ortega D and Bertagnolli MM: 2-Methoxyestradiol induces p53-associated apoptosis of colorectal cancer cells. Cancer Lett 187: 77-86, 2002. 
8. Lee YM, Ting CM, Cheng YK, Fan TP, Wong RN, Lung ML and Mak NK: Mechanisms of 2-methoxyestradiol-induced apoptosis and G2/M cell-cycle arrest of nasopharyngeal carcinoma cells. Cancer Lett 268: 295-307, 2008

9. Li L, Bu S, Bäckström T, Landström M, Ulmsten U and Fu X: Induction of apoptosis and $\mathrm{G} 2 / \mathrm{M}$ arrest by 2-methoxyestradiol in human cervical cancer HeLaS3 cells. Anticancer Res 24: 873-880, 2004.

10. Seeger H, Wallwiener D, Kraemer E and Mueck AO: Comparison of possible carcinogenic estradiol metabolites: Effects on proliferation, apoptosis and metastasis of human breast cancer cells. Maturitas 54: 72-77, 2006.

11. Minorics R, Bózsity N, Molnár J, Wölfling J, Mernyák E, Schneider G, Ocsovszki I and Zupkó I: A molecular understanding of D-homoestrone-induced G2/M cell cycle arrest in HeLa human cervical carcinoma cells. J Cell Mol Med 19: 2365-2374, 2015

12. Chang I, Majid S, Saini S, Zaman MS, Yamamura S, Chiyomaru T, Shahryari V, Fukuhara S, Deng G, Dahiya R and Tanaka Y: Hrk mediates 2-methoxyestradiol-induced mitochondrial apoptotic signaling in prostate cancer cells. Mol Cancer Ther 12: 1049-1059, 2013 .

13. Siebert AE, Sanchez AL, Dinda S and Moudgil VK: Effects of estrogen metabolite 2-methoxyestradiol on tumor suppressor protein p53 and proliferation of breast cancer cells. Syst Biol Reprod Med 57: 279-287, 2011.

14. Codogno P and Meijer AJ: Autophagy and signaling: Their role in cell survival and cell death. Cell Death Differ 12 (Suppl 2): S1509-S1518, 2005

15. Debatin KM and Krammer PH: Death receptors in chemotherapy and cancer. Oncogene 23: 2950-2966, 2004.

16. Maiuri MC, Zalckvar E, Kimchi A and Kroemer G: Self-eating and self-killing: Crosstalk between autophagy and apoptosis. Nat Rev Mol Cell Biol 8: 741-752, 2007.

17. Eisenberg-Lerner A, Bialik S, Simon HU and Kimchi A: Life and death partners: Apoptosis, autophagy and the cross-talk between them. Cell Death Differ 16: 966-975, 2009.

18. Chuang TD, Ho M and Khorram O: The regulatory function of miR-200c on inflammatory and cell-cycle associated genes in SK-LMS-1, a leiomyosarcoma cell line. Reprod Sci 22: 563-571, 2015.

19. D'Angelo E and Prat J: Uterine sarcomas: A review. Gynecol Oncol 116: 131-139, 2010

20. Segars JH, Parrott EC, Nagel JD, Guo XC, Gao X, Birnbaum LS, Pinn VW and Dixon D: Proceedings from the third national institutes of health international congress on advances in uterine leiomyoma research: Comprehensive review, conference summary and future recommendations. Hum Reprod Update 20: 309-333, 2014

21. Reichardt P: The treatment of uterine sarcomas. Ann Oncol 23 (Suppl 10): x151-x157, 2012.

22. Lee HG, Baek JW, Shin SJ, Kwon SH, Cha SD, Park WJ, Chung R, Choi ES, Lee GH and Cho CH: Antitumor effects of flavopirido on human uterine leiomyoma in vitro and in a xenograft model Reprod Sci 21: 1153-1160, 2014.

23. Oltvai ZN, Milliman CL and Korsmeyer SJ: Bcl-2 heterodimerizes in vivo with a conserved homolog, Bax, that accelerates programmed cell death. Cell 74: 609-619, 1993.

24. Rudel T: Caspase inhibitors in prevention of apoptosis. Herz 24: 236-241, 1999

25. Amaral JD, Xavier JM, Steer CJ and Rodrigues CM: The role of p53 in apoptosis. Discov Med 9: 145-152, 2010.

26. Deng X, Kornblau SM, Ruvolo PP and May WS Jr: Regulation of Bcl2 phosphorylation and potential significance for leukemic cell chemoresistance. J Natl Cancer Inst Monogr: 30-37, 2001.

27. Gao N, Rahmani M, Dent $P$ and Grant $S$ 2-Methoxyestradiol-induced apoptosis in human leukemia cells proceeds through a reactive oxygen species and Akt-dependent process. Oncogene 24: 3797-3809, 2005.
28. Kondo Y and Kondo S: Autophagy and cancer therapy. Autophagy 2: 85-90, 2006.

29. Salama SA, Nasr AB, Dubey RK and Al-Hendy A: Estrogen metabolite 2-methoxyestradiol induces apoptosis and inhibits cell proliferation and collagen production in rat and human leiomyoma cells: A potential medicinal treatment for uterine fibroids. J Soc Gynecol Investig 13: 542-550, 2006.

30. Robboy SJ, Bentley RC, Butnor K and Anderson MC: Pathology and pathophysiology of uterine smooth-muscle tumors. Environ Health Perspect 108 (Suppl 5): S779-S784, 2000.

31. Walker CL and Stewart EA: Uterine fibroids: The elephant in the room. Science 308: 1589-1592, 2005.

32. Akhan SE, Yavuz E, Tecer A, Iyibozkurt CA, Topuz S, Tuzlali S, Bengisu E and Berkman S: The expression of Ki-67, p53, estrogen and progesterone receptors affecting survival in uterine leiomyosarcomas. A clinicopathologic study. Gynecol Oncol 99: 36-42, 2005.

33. Reed JC, Talwar HS, Cuddy M, Baffy G, Williamson J, Rapp UR and Fisher GJ: Mitochondrial protein p26 BCL2 reduces growth factor requirements of NIH3T3 fibroblasts. Exp Cell Res 195: 277-283, 1991

34. Joubert A, Maritz C and Joubert F: Bax/Bcl-2 expression levels of 2-methoxyestradiol-exposed esophageal cancer cells. Biomed Res 26: 131-134, 2005.

35. Fukui M and Zhu BT: Mechanism of 2-methoxyestradiol-induced apoptosis and growth arrest in human breast cancer cells. Mol Carcinog 48: 66-78, 2009.

36. LaVallee TM, Zhan XH, Johnson MS, Herbstritt CJ, Swartz G, Williams MS, Hembrough WA, Green SJ and Pribluda VS: 2-methoxyestradiol up-regulates death receptor 5 and induces apoptosis through activation of the extrinsic pathway. Cancer Res 63: 468-475, 2003.

37. Porter AG and Jänicke RU: Emerging roles of caspase-3 in apoptosis. Cell Death Differ 6: 99-104, 1999.

38. Meloche S and Pouysségur J: The ERK1/2 mitogen-activated protein kinase pathway as a master regulator of the G1- to S-phase transition. Oncogene 26: 3227-3239, 2007.

39. Chen JR, Plotkin LI, Aguirre JI, Han L, Jilka RL, Kousteni S, Bellido T and Manolagas SC: Transient versus sustained phosphorylation and nuclear accumulation of ERKs underlie anti-versus pro-apoptotic effects of estrogens. J Biol Chem 280: 4632-4638, 2005.

40. Tsai SC, Huang WW, Huang WC, Lu CC, Chiang JH, Peng SF, Chung JG, Lin YH, Hsu YM, Amagaya $\mathrm{S}$ and Yang JS: ERK-modulated intrinsic signaling and $\mathrm{G}(2) / \mathrm{M}$ phase arrest contribute to the induction of apoptotic death by allyl isothiocyanate in MDA-MB-468 human breast adenocarcinoma cells. Int J Oncol 41: 2065-2072, 2012.

41. Tang D, Wu D, Hirao A, Lahti JM, Liu L, Mazza B, Kidd VJ, Mak TW and Ingram AJ: ERK activation mediates cell cycle arrest and apoptosis after DNA damage independently of p53. J Biol Chem 277: 12710-12717, 2002.

42. Hemmings BA: Akt signaling: Linking membrane events to life and death decisions. Science 275: 628-630, 1997.

43. Cagnol S and Chambard JC: ERK and cell death: Mechanisms of ERK-induced cell death-apoptosis, autophagy and senescence. FEBS J 277: 2-21, 2010

44. Cheng Y, Qiu F, Tashiro S, Onodera S and Ikejima T: ERK and JNK mediate TNFalpha-induced p53 activation in apoptotic and autophagic L929 cell death. Biochem Biophys Res Commun 376: 483-488, 2008

45. Lee JS, Kim YK, Yang H, Kang HY, Ahn C and Jeung EB: Two faces of the estrogen metabolite 2-methoxyestradiol in vitro and in vivo. Mol Med Rep 12: 5375-5382, 2015. 